\title{
Views on Early Diagnosis of Alzheimer's Disease Among Dutch Physicians: A Qualitative Interview Study
}

\author{
Krista Tromp ${ }^{\mathrm{a}, 1}$, Marthe Smedinga ${ }^{\mathrm{a}, \mathrm{b}, 1, *}$, Edo Richard $^{\mathrm{b}}$, Marieke Perry $^{\mathrm{c}, \mathrm{d}}$ \\ and Maartje H.N. Schermer ${ }^{\mathrm{a}}$ \\ ${ }^{a}$ Department of Medical Ethics and Philosophy and History of Medicine, Erasmus MC, Rotterdam, \\ the Netherlands \\ ${ }^{\mathrm{b}}$ Department of Neurology, Donders Institute for Brain, Cognition and Behaviour, Radboudumc, Nijmegen, \\ the Netherlands \\ ${ }^{\mathrm{c}}$ Department of Geriatric Medicine, Radboud Institute for Health Sciences, Radboudumc, Nijmegen, \\ the Netherlands \\ ${ }^{\mathrm{d}}$ Department of Primary and Community Care, Radboud Institute for Health Sciences, Radboudumc, \\ Nijmegen, the Netherlands
}

Accepted 10 November 2020

Pre-press 23 December 2020

\begin{abstract}
.
Background: Hope for future treatments to prevent or slow down dementia motivates researchers to strive for ever-earlier diagnoses of Alzheimer's disease (AD) based on biomarkers, even before symptoms occur. But is a biomarker-based early diagnosis desirable in clinical practice?

Objective: This study explores the ethical considerations that shape current clinical practice regarding early AD diagnostics and the use of biomarkers.

Methods: In this qualitative study, Dutch physicians were interviewed. Topics included physicians' views concerning early AD diagnosis in persons with no or mild cognitive impairment, physicians' considerations regarding current and expected future practices of early $\mathrm{AD}$ diagnosis, the use of biomarkers, and the use of the concepts preclinical and prodromal $\mathrm{AD}$. We analyzed the transcripts using directed content analysis.

Results: 15 general practitioners, neurologists, and geriatricians in the Netherlands were interviewed. Most of them interpreted an early $\mathrm{AD}$ diagnosis with an early diagnosis of dementia. We identified six clusters of considerations sometimes in favor but most often against pursuing an early AD diagnosis in people with no or mild cognitive impairment that influence physicians' diagnostic decision-making: preferences and characteristics of persons, test characteristics, impact on care, type of setting, disease concepts, and issues on a societal level.

Conclusion: The discussion concerning an early AD diagnosis based on biomarkers which is widely held in the scientific field, has not entered clinical practice structurally. A biomarker-based early diagnosis does not fit within Dutch physicians' views on what good care for people with no, subjective, or mild cognitive impairment should entail.
\end{abstract}

Keywords: Alzheimer's disease, biomarkers, decision-making, early diagnosis, ethics

\section{INTRODUCTION}

\footnotetext{
${ }^{1}$ These authors contributed equally to this work.

*Correspondence to: Marthe Smedinga, Department of Neurology, Donders Institute for Brain, Cognition and Behaviour, Radboudumc, Nijmegen, the Netherlands. E-mail: marthe.sme dinga@radboudumc.nl.
}

In the hope for future treatments to prevent or slow down dementia, there is a strong movement toward an ever-earlier diagnosis of Alzheimer's disease (AD), even before symptoms occur. But should we pursue such an early diagnosis in clinical practice, and is this ethically desirable? 
The focus on an early diagnosis of AD caused a shift in the definition of the disease in the research setting [1]. AD has long been defined by clinical symptoms of cognitive impairment and functional decline, but now researchers increasingly base the diagnosis in a research setting on biological measures (biomarkers) [1]. It has become possible to detect these biomarkers, e.g. amyloid- $\beta$ and tau, in cerebrospinal fluid or on neuroimaging with a positron emission tomography (PET) scan, that are presumed to reflect brain changes eventually leading to dementia, in persons with no or only mild cognitive impairment. This has led to a reconceptualization of $\mathrm{AD}$, and newly proposed concepts of 'preclinical' and 'prodromal' AD for those who test positive of AD biomarkers but have no dementia [2]. While currently mainly used in research, these biomarkers and the concepts of preclinical and prodromal $\mathrm{AD}$ are moving into clinical practice [3-5]. Specific efforts are being made to set up action plans - a strategic research agenda or roadmap-to accelerate the adoption of these $\mathrm{AD}$ biomarkers in clinical practice [6].

This transition of early AD diagnostics into clinical practice raises both questions of (scientific) validity as of (ethical) desirability. Most research looks at the former, mainly focused on diagnostic accuracy: What is the added diagnostic value of specific biomarkers $[5,7]$ ? However, much less attention is paid to the latter questions: Is this shift to an ever earlier diagnosis of $\mathrm{AD}$ desirable and worth pursuing? What is the value of knowing such a diagnosis, what are the harms and benefits? These types of questions are crucial to ask and answer before embedding $\mathrm{AD}$ biomarker testing in clinical practice.

While questions concerning desirability of early AD diagnostics in clinical practice have been addressed by scholars from ethics and social science [8-10], little empirical research is done to inform this ethical debate. The empirical research that is performed up until now focuses mostly on those receiving biomarker testing (patients); not on those providing biomarker testing (medical practitioners) [11]. Knowledge of current clinical practices regarding early $\mathrm{AD}$ diagnostics and the use of $\mathrm{AD}$ biomarkers in persons with no or mild cognitive impairment, as well as of the scientific and ethical reasoning behind this practice as seen from the point of view of medical practitioners, is scarce [8]. In order to investigate the desirability of early AD diagnostics and the use of AD biomarkers, it is essential to first establish how it would fit within current clinical practice and to take the perspectives and arguments from those involved in that practice into account [12].

Therefore, this study aimed to explore the considerations that shape current clinical practice regarding early $\mathrm{AD}$ diagnostics and the use of $\mathrm{AD}$ biomarkers. We focused on physicians' views concerning early $\mathrm{AD}$ diagnosis in persons with no or mild cognitive impairment, physician's considerations regarding current and future practices of early $\mathrm{AD}$ diagnosis, the use of biomarkers, and the use of the concepts preclinical and prodromal AD.

\section{METHODS}

This qualitative interview study is reported in accordance with the consolidated criteria for reporting qualitative research (COREQ) [13]. Contributing researchers are trained and experienced in qualitative research methodology, medical ethics, health and neuroscience, or medicine.

\section{Study setting and population}

Between July 2017 and February 2018, we recruited physicians (general practitioners, geriatricians, and neurologists) in the Netherlands who routinely perform diagnostics in patients with memory complaints or have reasonable experience with diagnostics in dementia. In the Netherlands, dementia can be diagnosed and consequently followed-up either by a general practitioner or a medical specialist according to current guidelines. Additionally, patients need a referral from a GP to visit a specialized memory clinic. Relevant national guidelines are the guideline of general practitioners [NHG standaard Dementie], 2012; the multidisciplinary guideline [Dementie], 2014; and its addendum [Addendum Mild Cognitive Impairment], 2017. We invited physicians by email with information about the goal and content of the interview and overarching research project, and the question to participate in the interview study.

To do justice to the variety of clinical practice and to ensure a wide range of perspectives, we used purposive sampling for the selection of the study population [14]. Characteristics taken into account for this sample were: physician's specialism (general practitioners, geriatricians, neurologists); gender; years of work experience (ample diversity in experience); location (scattered around the Netherlands); and setting (general practice, academic and community hospitals). 
Table 1

Vignettes (what would you do and why?)

\begin{tabular}{ll}
\hline $\begin{array}{l}\text { Specialism } \\
\text { of interviewee }\end{array}$ & Vignette \\
\hline $\begin{array}{l}\text { General } \\
\text { practitioner }\end{array}$ & A 74 -year-old man, with only a gallbladder operation 20 years ago \\
in his medical history, comes to you with memory complaints. \\
He is worried about this. \\
A 74 -year-old man, with only a gallbladder operation 20 years ago in his medical \\
history, has visited his general practitioner because of memory complaints. \\
At the GP the MMSE was $29 / 30$ and the clock drawing test was performed well. \\
It has been decided to refer the man to you as a neurologist \\
because of the memory complaints. \\
A 74 -year-old man, with only a gallbladder operation 20 years ago \\
in his medical history, has visited his general practitioner because \\
of memory complaints. At the GP the MMSE was 29/30 and the clock \\
drawing test was performed well. It has been decided to refer \\
the man to you as a geriatrician because of the memory complaints.
\end{tabular}

We ended enrolment of participants when theoretical saturation was reached for answering the main research question and no new concepts emerged [15]. When no new concepts emerged, we performed one additional interview to confirm saturation.

This qualitative interview study was deemed exempt from ethics approval by the research ethics committee of the Erasmus Medical Center (protocol number: MEC-2017-272). Oral informed consent was obtained from all physicians before the interview commenced. All was in accordance with Dutch legislation for medical research with humans.

\section{Data collection}

Two researchers (KT and/or MS), trained and experienced in interviewing techniques, conducted semi-structured interviews with physicians in a private setting at their office or at home. Interviews lasted approximately 1 hour. To elucidate the considerations of physicians regarding early $\mathrm{AD}$ diagnosis, the interview guide included three parts: 1) Practice of diagnostics; 2) Terminology; 3) Expectations for the future (Supplementary Table 1). Part 1 of the interview commenced with a vignette, adapted per specialism to start the discussion (Table 1). These vignettes included a standardized case description of an older person with memory complaints for which the physician was asked what he/she would do and why. Part 2 included a discussion about used and preferred terminology (e.g., preclinical AD, prodromal AD, MCI). Part 3 included reflections on the future of AD diagnostics (including hopes, doom scenarios, and reality). The interviews were audio taped and transcribed verbatim.

\section{Analysis}

We analyzed the interviews using directed content analysis [16]. The initial coding tree was based on the interview guide and included: 1) Response to vignette; 2) Considerations for diagnostic choices; 3 ) Terminology; 4) Expectations, hopes, and concerns for the future. The subcoding tree for the considerations for diagnostic choices in this directed approach was based on previous research of the authors, including a systematic literature review of ethical arguments in favor or against $\mathrm{AD}$ biomarker testing in people with no or mild cognitive impairment [17]. To do justice to new emerging concepts, open coding was used when the considerations did not match the initial subcoding tree.

In the first phase of coding and analysis, two researchers (KT and MS) both independently coded two interviews to limit the risk of bias and subjectivity in the analysis. We adapted and elaborated the initial coding tree based on data from these two interviews. Disagreements were settled by consensus. This coding tree was discussed with the other researchers (MP, ER, and MHS).

In the second phase, the remaining interviews were coded by MS and subsequently reviewed by KT. Disagreements were settled by consensus. This coding was based on the initial coding tree that was adapted and elaborated based on new concepts emerging from the data.

In the third phase, axial coding of the data was performed to identify clusters of considerations in the interviews. KT performed this coding, and it was reviewed by MS and discussed with MHS and MP. Disagreements were settled by consensus. 
Coding and analysis continued until no new codes, concepts, or patterns could be identified from the data. The process of analysis was supported by QSR International's NVivo 11 qualitative data analysis Software [18].

\section{RESULTS}

\section{Study population}

Between July 2017 and February 2018, we approached 21 potential participants. Four physicians did not respond to our request and two declined participation because of time constraints. Eventually, 15 physicians participated in this interview study. We interviewed five general practitioners (GPs), six geriatricians, and four neurologists. Six of them were female and nine were male. Of the medical specialists, four currently worked in an academic hospital and six in a community hospital. Their work experience as a physician ranged from 8 to 35 years; their experience in the field of dementia ranged from 5 to 35 years. They were all experienced in dementia diagnostics, but variation within the group was present concerning depth and frequency of these practices. Due to the large risk of identification of interviewees in a small country as the Netherlands, no table illustrating the characteristics per individual was added.

\section{Use of AD terminology}

Analysis of the interviews shows that use of terminology related to $\mathrm{AD}$ is very diverse among the participants and inconsistent, even within a person. Participants often use analogies with other diseases (e.g., diabetes, cardiovascular diseases, or cancer) to explain the disease concepts they prefer to use. Preferred terminology and considerations concerning desirability are related to each other, e.g., the used analogy explained the choice for a specific care plan. Table 2 contains illustrative quotes concerning AD terminology.

First, interviewees differ in their definition of AD. For example, one interviewee mentions to have found evidence for $\mathrm{AD}$ in a cognitively healthy individual; he uses a biological definition of AD. Others said biomarkers had no additional value, because an $\mathrm{AD}$ diagnosis can only be based on clinical symptoms of dementia; they use a clinical definition of AD.

Second, almost none of the interviewed physicians associate 'early AD diagnosis' with making a diagnosis before symptoms arise. Most of them associate the term 'early AD diagnosis' with early signaling of dementia or other cognitive impairment: the early detection of problematic functional signs in daily living that indicate something is wrong in daily life (e.g., forgetting appointments, unkempt appearance).

Third, few of the interviewed physicians know the difference between preclinical and prodromal AD. Two interviewees acknowledge using these terms, but none of the physicians use the terms in their communication with patients. After explanations of concepts, most of the participants would not deem these terminologies fit to use in clinical practice (neither with colleagues nor with patients), mostly because it would cause misunderstanding and worries about the future. Physicians make a clear distinction between the usefulness of these terms for clinical practice and in research. They do recognize the usefulness of the terms in the research setting.

\section{Clusters of considerations concerning early $A D$ diagnosis}

Directed content analysis revealed six clusters of considerations concerning the desirability of early $\mathrm{AD}$ diagnosis in persons with no or mild cognitive impairment that influence physicians' diagnostic decision-making. They relate to person (seeking medical help), test, care, setting, disease, and society. An overview of these clusters (axial coding tree) is shown in Table 3. Table 4 contains illustrative quotes per cluster.

\section{Cluster 1: Person-related considerations}

Many of the considerations concerning the desirability of an early $\mathrm{AD}$ diagnosis are related to the person seeking medical help (person-related considerations). These considerations can be categorized into preferences of the person and characteristics of the person.

First reactions to the vignettes are mostly related to the existence of a request for help from the person (or family members). Interviewees' first action would be to ask the person what their request for help would be. Why are they here, what are they worried about, and what do they want from their physician? All physicians have a strong emphasis on addressing and respecting the wishes of the person. Wishes explicitly mentioned by interviewed physicians influencing their decision for diagnostic work-up include a person's (lack of) desire to know, and desire for reassurance. 
Table 2

Examples of use of AD related terminology

\begin{tabular}{|c|c|}
\hline $\begin{array}{l}\text { Terminology } \\
\text { Definition of AD }\end{array}$ & Quote \\
\hline Alzheimer - dementia & $\begin{array}{l}\text { "Dementia is... Alzheimer's Disease is.... dementia is in any case a clinical condition, } \\
\text { 'so you'll have to have symptoms for that. Alzheimer's is of course a disease, so in that sense } \\
\text { you could diagnose Alzheimer's before someone has a dementia and notices that he is going to get it. } \\
\text { I don't see those people, luckily I would almost say, because it seems like a huge drama to tell people } \\
\text { two years before they get dementia that they have Alzheimer's Disease." } \\
\text { (geriatrician, ID-No. 34) }\end{array}$ \\
\hline Alzheimer - dementia & $\begin{array}{l}\text { "And it is true that I, that if you really diagnose dementia, then you first diagnose dementia and } \\
\text { then you can think: 'Yes, I think this is typically more of an Alzheimer's pattern or I find this more } \\
\text { of a typical vascular pattern.' But I think if you cut those heads open then it's all } \\
\text { a bit of this and a bit of that. So I actually mainly use the diagnosis dementia and not } \\
\text { just Alzheimer's Disease." } \\
\text { (general practitioner, ID-No. 14) }\end{array}$ \\
\hline Analogies & $\begin{array}{l}\text { "No, because then you call it a so-called non-dementia Alzheimer's Disease. So you do have } \\
\text { Alzheimer's Disease, but you are not demented. That is quite interesting... You are sero positive } \\
\text { but you do not yet have HIV." } \\
\text { (geriatrician, ID-No. 32) }\end{array}$ \\
\hline Analogies & $\begin{array}{l}\text { "We've got our hands full with treating people with hypertension and diabetes, we are not at } \\
\text { all waiting for 'pre-conditions', and that also applies to dementia as far as I am concerned." } \\
\text { (geriatrician, ID-No. 33) }\end{array}$ \\
\hline Early signalling & $\begin{array}{l}\text { "So is it that when he meets someone on the street that he doesn't come up with that name, } \\
\text { or does he forget the name of his children? That makes quite a difference. And do other things } \\
\text { go wrong? So things go wrong not only in cognitive but also in executive functions?... Uhm, and based } \\
\text { on that I make an assessment as to whether I am actually thinking of a real memory problem." } \\
\text { (general practitioner, ID-No. 12) }\end{array}$ \\
\hline $\begin{array}{l}\text { Preclinical and } \\
\text { prodromal AD }\end{array}$ & $\begin{array}{l}\text { "II do not use preclinical and prodromal] ... no. If it is a diagnosis it must be a hard one and } \\
\text { then there must be consequences to it." } \\
\text { (neurologist, ID-No. 24) }\end{array}$ \\
\hline Other terminology & $\begin{array}{l}\text { "Then I have to pay close attention to what I write down, because if I know of that person that Alzheimer's } \\
\text { is a kind of specter and I [write that down], well then he will have a depression in no time. } \\
\text { And if I choose terms like: 'your memory rattles so you don't remember things quite well and that makes } \\
\text { you anxious and restless,' if that is noted for that person and that helps, then I write that down." } \\
\text { (general practitioner, ID-No. 13) }\end{array}$ \\
\hline
\end{tabular}

Table 3

Clusters of considerations overview (axial coding tree)

\begin{tabular}{|c|c|c|}
\hline \multicolumn{2}{|c|}{ PERSON-related } & TEST-related \\
\hline $\begin{array}{l}\text { Characteristics } \\
\text { Presence and severity of symptoms } \\
\text { Presence and severity of signaling issues } \\
\text { Age } \\
\text { Level of education } \\
\text { Personal background }\end{array}$ & $\begin{array}{l}\text { Preferences / whishes } \\
\text { Request for help } \\
\text { Reassurance (of family) } \\
\text { Patient wants / doesn't want to know }\end{array}$ & $\begin{array}{l}\text { Test-specific issues } \\
\text { Risk and burden of the test } \\
\text { Diagnostic accuracy } \\
\text { Costs of the test }\end{array}$ \\
\hline CARE - related & & SETTING - related \\
\hline $\begin{array}{l}\text { Exclude other possible causes } \\
\text { Relevance of specifying dementia subtype } \\
\text { Provide (or lack of) preventive treatment } \\
\text { Provide (or lack of) other health benefits } \\
\text { Increased planning possibilities } \\
\text { Offer practical guidance and support } \\
\text { Provide comfort and enable acceptance }\end{array}$ & & $\begin{array}{l}\text { Research } \\
\text { Population screening } \\
\text { General practice } \\
\text { Hospital - specialist } \\
\text { Official guidelines } \\
\text { Local protocol or individual physician habits }\end{array}$ \\
\hline DISEASE - related & & SOCIETY - related \\
\hline $\begin{array}{l}\text { Difference disease and normal ageing } \\
\text { Effect of label/diagnosis } \\
\text { Specific terminology }\end{array}$ & & $\begin{array}{l}\text { Costs of care } \\
\text { Medicalization/medical interfering } \\
\text { Influence of media and other powers }\end{array}$ \\
\hline
\end{tabular}


Table 4

Examples of considerations

\begin{tabular}{l} 
(Cluster of) Consideration \\
\hline Person-related considerations
\end{tabular}

Characteristics - age

Characteristics and preferences

Preferences - patient wants to

Preferences - request for help

\section{Quote}

"If you see someone aged 85 and you are going to do that, well, what do you want to achieve with that? Then it could well be that Alzheimer's abnormalities are found in the CSF, while it is not said at all that that patient suffers from Alzheimer's Disease, because that is something else." (neurologist, ID-No. 22)

"And with aging... I think... it's linked to age too. Cognitive decline and Alzheimer's, that's just an age disease you could almost say. And those older people are waiting much less for all kinds of diagnostics than we do, I would almost say. Look, when you are 50, 60 and you are very anxious because you have seen a lot of dementia in your surroundings or you are very afraid that you will get it and you absolutely do not want that, then you may want to have those biomarkers checked." (geriatrician, ID-No. 31)

“... On the other hand, I am also very much in favor of it ... I mean, I won't be someone who says you can't, because I don't support that, not that. If people have good arguments and say that it feels good to them, then I would like to do that, then I think that's fine." (general practitioner, ID-No. 14)

"You can ask people that: 'Oh what makes you come here now, what do you expect from me?' I can think of all sorts of things, but before I get started right away: 'I [...] am just curious what you would like me to do. And when will you leave satisfied?' [...] If people come themselves, it is rare for dementia to occur. When people come themselves, it is usually fear of dementia." (general practitioner, ID-No. 13)

Test-related considerations

Diagnostic accuracy - certainty

"The technical assessment is actually such that it is not necessary, not strictly necessary. And in that respect, there is a kind of ambiguity, even within myself. That on the one hand I think it is not really necessary, it will not produce anything, sometimes I actually said that in advance: 'I do not expect any miracles and you must not either, but we do it just to be sure'.. ", (neurologist, ID-No. 21)

Risk and burden of test

"And I think that this kind of diagnostic work-up [conversation at home with MMSE] is much more pleasant for that lady and for that family, than hoisting someone like that in a bus to the hospital and pulling them through a scan and doing an amyloid measurement and an LP that does not add much more" (geriatrician, ID-No. 33)

Costs of the test

"Well that means if you can do it with simpler diagnostics: a CT instead of an MRI, no PET, no lumbar puncture, just wait and see, let time do its work, then that ... will cost less without harming your patient." (geriatrician, ID-No. 34)

Care-related considerations

Lack of therapy

"My expectation is actually that we let those biomarkers fade into the background, which is the opposite of what a geriatrician probably thinks. Because it makes no sense at all in this aging society to do a lot of early diagnostics, because we don't have any medication yet either to slow it down. Those plasters don't help at all.. There is nothing else. So when there is treatment, it makes sense to do early diagnostics, but at the moment it has no added value at all." (general practitioner, ID-No. 12)

Lack of benefit

"So then I think, yes then you can impose that on someone and say: 'Look, you have a dementia label.' But it must have a function, or it must be able to contribute to a better happiness, so to speak." (general practitioner, ID-No. 14)

Provide other benefits offer support

"Because now we also do not have a treatment and yet we make the diagnosis. Because I think making the diagnosis is of added value. And that added value is not so much in prescribing someone pills or sticking plasters ... . But it can help to get an indication to arrange better healthcare." (geriatrician, ID-No. 33)

General practice

"From the world of dementia professionals, early diagnostics is a bit sacred, isn't it?

There must be early diagnostics... but the GPs are also the group that sees that not much works. So they have something like yes I can send a person to the hospital, but what does that specialist do? Yes, a battery of tests and they can't do anything else... So that does not motivate a general practitioner." (geriatrician, ID-No. 31) 
Table 4

Continued

\begin{tabular}{|c|c|}
\hline (Cluster of) Consideration & Quote \\
\hline \multicolumn{2}{|l|}{ Setting-related considerations } \\
\hline Research purpose & $\begin{array}{l}\text { "Or if someone says I want to know because I am considering to take part in a trial with } \\
\text { some new medicine in [tertiary memory clinic]. Yes, I also think that is a valid argument." } \\
\text { (neurologist, ID-No. 22) }\end{array}$ \\
\hline Official guideline & $\begin{array}{l}\text { "I am not entirely up-to-date with the latest state of science in this area. So I follow the guideline, } \\
\text { which is now just three years or a little older." } \\
\text { (geriatrician, ID-No. 34) }\end{array}$ \\
\hline \multicolumn{2}{|c|}{ Disease-related considerations } \\
\hline Disease - normal ageing & $\begin{array}{l}\text { "In my opinion, we are talking about an aging condition. So we make... we have developed a lot } \\
\text { as doctors that make people get older and I think Alzheimer's really is an aging condition that of } \\
\text { course involves all kinds of things in our society, but ultimately because people get old enough. } \\
\text { That's just like those people with a prostate [cancer], if you grow old enough then you die with } \\
\text { Alzheimer's. [... I Yes, I think that indeed makes my opinion different from someone } \\
\text { who sees it as a disease [...] yes I mean Alzheimer's is a part predisposition, } \\
\text { a part environment, part aging, there are a lot of things." } \\
\text { (general practitioner, ID-No. 13) }\end{array}$ \\
\hline Effect of label - diagnosis & $\begin{array}{l}\text { "It may help to make an early diagnosis [ ... ] but then how early do you want to know that } \\
\text { you have Alzheimer's Disease? Don't you give more disease burden to a patient who } \\
\text { is not yet ill at all, which I have experienced very strongly with this patient." } \\
\text { (general practitioner, ID-No. 12) }\end{array}$ \\
\hline \multicolumn{2}{|l|}{ Society-related considerations } \\
\hline Medicalization & $\begin{array}{l}\text { "Because it is apparently not yet an issue for the patient. And that has something to do } \\
\text { with when you notice early if someone has Alzheimer's disease, people are sick for a longer } \\
\text { time. [ ... I I do not use them and as far as I know there are no significant markers. } \\
\text { And I am a general practitioner, so I think you should let people be sick } \\
\text { for as short a time as possible." } \\
\text { (general practitioner, ID-No. 15) }\end{array}$ \\
\hline Medicalization & $\begin{array}{l}\text { "I think that is a flaw of this modern age, the misconception that knowledge } \\
\text { makes you happier." } \\
\text { (neurologist, ID-No. 24) }\end{array}$ \\
\hline $\begin{array}{l}\text { Influence of media } \\
\text { and other powers }\end{array}$ & $\begin{array}{l}\text { "And you see the same thing with people with diabetes... and a driver behind that to } \\
\text { help these kinds of entities into the world... are often, certainly in the world of hypertension } \\
\text { and diabetes, driven by pharmaceutical companies that want to expand the market and not } \\
\text { at all by doctors who are waiting for: 'O yes now we can do something" " } \\
\text { (geriatrician, ID-No. 33) }\end{array}$ \\
\hline $\begin{array}{l}\text { Influence of media } \\
\text { and other powers }\end{array}$ & $\begin{array}{l}\text { "Well, I find that is very much inclined towards... because that, of course, also comes } \\
\text { from somewhere, then I didn't force it upon him or her as an agency or as a professional, } \\
\text { but then others forced it upon him or her." } \\
\text { (neurologist, ID-No. 21) }\end{array}$ \\
\hline
\end{tabular}

Additionally, the interviewees all want to find out the presence and severity of the symptoms (e.g., memory complaints, limitations in daily functions) and explore other signaling issues (e.g., unkempt appearance, spoiled food in refrigerator). Even when the interviewer emphasizes that no symptoms or other signals are presented in the vignette, they keep circling back to situations in which individuals show symptoms and give arguments for their decision making in a scenario where a person shows symptoms. A higher age is a characteristic that is mentioned regularly as a strong indicator for the physician not to consider and pursue an early $\mathrm{AD}$ diagnosis by use of biomarkers, because of two reasons: symptoms are considered a part of normal aging, and there is a strong likelihood for multifactorial causes of symptoms. Other person-characteristics mentioned by the interviewees as influencing their decision include the level of education and personal background of the person seeking medical help.

\section{Cluster 2: Test-related considerations}

Many of the interviewees think that a biomarker does not have additional value in the diagnostic process, especially in older age. The (lack of) diagnostic accuracy (including validity and test-performance) is an important test-related consideration influencing their decision making. Other test-related considerations include arguments on the costs of such tests, the risk and burden of these tests, and test-specific issues. 
There is a large variability in knowledge among physicians concerning biomarkers. Additionally, they also value this knowledge differently: Interviewees consider different levels of test characteristics as sufficient or adequate for implementation of a test in clinical practice. For example, some refer to a specific percentage of sensitivity as enough evidence to implement a test, while others refer to that same specific number of that test as not enough evidence for implementation. When discussing diagnostic or prognostic testing for $\mathrm{AD}$, most interviewees refer to memory testing. Rarely interviewees brought up the use of biomarkers in this context and if so, they only referred to CSF testing for exceptional cases. Most of them do not know details about specific neuroimaging biomarkers like PET-scans. Genetic testing for $A P O E$ $\varepsilon 4$, which indicates an increased risk to develop AD dementia, was also not considered.

Although costs are not mentioned as a factor in individual decision-making or in referring a person, costs (specifically of PET-Amyloid) are mentioned on a societal level, especially when one considers screening for $\mathrm{AD}$ in the general population as a future scenario. Physicians also emphasize that the risks and burdens of these biomarker tests should be taken into consideration.

\section{Cluster 3: Care related considerations}

Some of the considerations the interviewed physicians mention are specifically care-oriented: what do we aim at by pursuing an early $\mathrm{AD}$ diagnosis? These considerations all center on the care that can and should be offered when pursuing an AD diagnosis. Although the interview focused on those with no or mild cognitive impairment who seek medical attention, some interviewees mention specifically that it is crucial to specify the dementia subtype for those with cognitive impairment, and that you can and should use biomarkers for that purpose. While others mention the opposite: specifying dementia subtypes will have no impact on the care trajectory, therefore there is no reason to pursue a biomarker test not even in those with cognitive impairment.

The current lack of preventive therapies and other health benefits is the major reason for interviewees for not considering early AD diagnosis or AD biomarkers ready for implementation in clinical practice. You don't have anything to offer to individuals. One interviewee argues the opposite: there are some preventive measures to slow down the progression. Also, the possibility of adapting your planning and giving guidance and support can be considered a benefit of an early diagnosis according to some interviewees. Providing comfort and enabling acceptance for both the individual as family members is also a reason for interviewees to pursue an early diagnosis, but only when diagnostic certainty could be guaranteed. Large diversity exists in whether the expectations of developing a possible treatment for AD in the future are realistic. Some argue the finding of a treatment is near, others wonder whether we will ever find a cure or preventive measure.

\section{Cluster 4: Setting-related considerations}

Interviewed physicians always refer to characteristics of a specific setting or scenario when they give arguments for their decision. They often explicitly distinguish between a research setting and a clinical setting. Also, a potential population screening offer is mentioned as a setting in which their considerations would differ. Interviewees also make explicit reference to differences in specialties. For example, the strength of the continuous relationship between patient and GP and repetitive contact moments in the GP setting makes the added value of biomarkers redundant to some physicians. Interviewees claim that with a proper follow up they can be equally or even better informed than with a biomarker result. Others refer to the (un)availability of and expertise in specific imaging techniques in their specialty. Also, physicians refer to current national guidelines and local protocols when asked to elucidate their choices. They justify their choice of action by referring and adhering to these documents.

\section{Cluster 5: Disease-related considerations}

A fifth cluster of considerations is related to disease-concepts, that is, interviewees' (implicit) norms on what should be considered a disease and what is part of normal aging. Many times, when physicians exemplify their reasons for not applying (biomarkers for) an early $\mathrm{AD}$ diagnosis, they refer to the fact that they consider the mild symptoms to be normal aging, especially in the older population. When symptoms are ascribed to normal aging, individuals should not be exposed to unnecessary medical scrutiny. The desirability of biomarker testing is strongly dependent on whether an interviewee frames it as testing for a diagnostic purpose or prognostic purpose. For example, physicians said that with AD biomarker testing you test for a risk for developing a disease, not for a disease in itself. Also, the possible negative effects of a diagnosis (or label) itself is mentioned in their argumentation for not considering an early diagnosis desirable. 


\section{Cluster 6: Society-related considerations}

A final cluster of considerations concerns reference to society as a whole. Fear of medicalization is mentioned by interviewed physicians as an important factor for not pursuing an early AD diagnosis in their patients. This argument is closely linked to disease-concepts and the difference between disease and normal aging. They emphasize that this shift toward an ever earlier diagnosis stems from a tendency to medicalize everything and the concern is that medical testing would bring more harm than good for the individual and society. Other societal considerations are concerned with the costs of and access to possible new treatments and whether or not science should invest in finding a (preventive) treatment for $\mathrm{AD}$ or rather focus on improving care and support. Physicians also mention the influence that the media and other powers (e.g., pharmaceutical companies) have on both medical practitioners and patients and how this can affect how people view the desirability of pursuing an early $\mathrm{AD}$ diagnosis.

\section{DISCUSSION}

Our study shows that the arguments Dutch physicians use in favor and against pursuing an early $\mathrm{AD}$ diagnosis in persons with no or mild cognitive impairment and testing AD biomarkers in clinical practice transcend the commonly used arguments in scientific literature. Arguments used in the literature mostly relate to validity and test performance of these biomarkers $[5-7,19]$. The interviewed physicians in our study used much more diverse arguments to explicate their normative stance toward early $\mathrm{AD}$ diagnosis and biomarkers in clinical practice. They emphasized for example the (lack of) impact of biomarker testing and early $\mathrm{AD}$ diagnosis on patient care and care trajectories. These arguments were categorized as care-related arguments in the results section and can be linked to the ethical principle of beneficence. Physicians who were relatively skeptical about a future rise of biomarker testing expressed doubts on whether this would be a just use of scarce healthcare resources. This concern can be linked to the ethical principle of justice. Additionally, the importance of meeting a person's wishes-thereby respecting his/her autonomy-was an important reason for physicians to decide about pursuing biomarker testing. Previous research concluded that whether biomarker testing for early AD diagnosis is desirable, depends on the individual context in which testing is considered [17]. The six clusters identified in this interview study (person, disease, test characteristics, setting, care, and society related arguments) give a more focused and detailed description of this individual context and show the normative angle in the argumentation of physicians concerning desirability of pursuing an early AD diagnosis in clinical practice. The variety in physicians' considerations shows us which values are taken into account when aiming to incorporate AD biomarkers in clinical practice. Physician's arguments are relevant in the debate on the ethical desirability of AD biomarker testing because they have moral experience with diagnosis of and care for people with cognitive complaints. Furthermore, if $\mathrm{AD}$ biomarker testing is pursued in clinical practice, it should fit their practice in a responsible way.

We designed this study in light of the rise of biomarker testing for early $\mathrm{AD}$ diagnosis in people without dementia that is described in research [1, 6]. However, most interviewed physicians, from primary to tertiary care and with diverse specialties, do not associate early AD diagnosis with setting a diagnosis in people without dementia. To most interviewed physicians, according to whom AD refers to dementia, 'early' refers to an early stage of dementia. Therefore, for them an early AD diagnosis means early signaling of dementia and MCI: the early detection of problematic functional signs. In contrast to what is described in some research on clinical utility of AD biomarker testing [20], people with no objective symptoms (who are curious to know their AD risk status) did not seem to fit within their framework of reference. Consequently, most of the interviewees did not pursue early diagnosis of $\mathrm{AD}$ in a stage before early dementia. This observation is in line with the two parallel definitions for AD that are currently being applied: A definition of AD that also applies to people with no or mild cognitive impairment based on biomarker status [1]; and a definition of AD that relies on clinical symptoms of dementia [21]. Our results show how miscommunication may arise when these definitions, meant for different settings, would be used simultaneously in a clinical setting, i.e., some physicians might diagnose a patient with "preclinical AD', while others would not diagnose the same person at all, and consider them healthy. Moreover, there are strong reasons to indeed limit the biological definition of $\mathrm{AD}$ to be only used in the research setting because of the potential negative consequences of an $\mathrm{AD}$ diagnosis for people with subjective or mild cognitive impairment in absence of an effective treatment 
$[2,22]$. Therefore, and in line with previous recommendations by Alzheimer Europe [23], the results from this interview study do not support the use of proposed new disease categories prodromal $\mathrm{AD}$ or preclinical AD in clinical practice.

Our results thus show that the discussion concerning a diagnosis of $\mathrm{AD}$ based on biomarkers which is widely held in the scientific field, has not entered Dutch clinical practice structurally. In the researchcommunity, there is a tendency by some scholars to expect and promote a wider implementation of AD biomarkers in clinical practice [6]. This tendency relies on the assumption that there are a lot of people with no or subjective cognitive impairment who would appreciate a diagnosis before symptoms and would visit a physician for this. In contrast, physicians interviewed in this study are hardly ever confronted with people with these requests. This exposes an additional mismatch of views presented by researchers in the scientific literature [6, 19, 24], with views held by physicians in wider clinical practice. The considerations that shape the practice of physicians working routine clinical care, as described above, may broaden the perspective of physicians working in memory clinics, who are familiar with a relatively narrow patient population, and researchers.

Strengths of this study include data-triangulation and the combination of experiences from clinical practice with analysis of moral reasoning. Also, the involvement of a multidisciplinary research team contributed to addressing the issue of early AD diagnosis in clinical practice from diverse relevant angles. A potential weakness of the study is the inability to translate and apply the findings to other countries, as the study only concerns the views of physicians in the Netherlands and the practice of AD diagnostics is to some extent country specific. Justice related considerations including the costs of biomarker testing or insurance related issues, for example, differ per country.

\section{CONCLUSION}

The possibility to diagnose $\mathrm{AD}$ in people with subjective or mild cognitive impairment based on biomarker results in clinical practice is increasingly presented as an ideal in scientific literature [20,24]. This ideal seems not in line with current clinical practice in the Netherlands. More importantly, it does not fit with views of Dutch physicians on what good care for people with no, subjective, or mild cognitive impairment should entail. This discrepancy between research expectations and clinical practice needs to be addressed by physicians, researchers, and policy makers to avoid false expectations in patients. In dealing with this discrepancy, clinicians' expertise regarding what 'good care' consists of, should be taken very seriously.

\section{ACKNOWLEDGMENTS}

We thank all physicians who were willing to participate in the interview study. This research is supported by a grant from The Netherlands Organization for Health Research and Development (grant number: 731010012).

Authors' disclosures available online (https:// www.j-alz.com/manuscript-disclosures/20-0884r1)

\section{SUPPLEMENTARY MATERIAL}

The supplementary material is available in the electronic version of this article: https://dx.doi.org/ 10.3233/JAD-200884.

\section{REFERENCES}

[1] Jack CR, Jr., Bennett DA, Blennow K, Carrillo MC, Dunn B, Haeberlein SB, Holtzman DM, Jagust W, Jessen F, Karlawish J, Liu E, Molinuevo JL, Montine T, Phelps C, Rankin KP, Rowe CC, Scheltens P, Siemers E, Snyder HM, Sperling R, Contributors (2018) NIA-AA Research Framework: Toward a biological definition of Alzheimer's disease. Alzheimers Dement 14, 535-562.

[2] Schermer MHN, Richard E (2019) On the reconceptualization of Alzheimer's disease. Bioethics 33, 138-145.

[3] Somers C, Struyfs H, Goossens J, Niemantsverdriet E, Luyckx J, De Roeck N, De Roeck E, De Vil B, Cras P, Martin JJ, De Deyn PP, Bjerke M, Engelborghs S (2016) A decade of cerebrospinal fluid biomarkers for Alzheimer's disease in Belgium. J Alzheimers Dis 54, 383-395.

[4] Niemantsverdriet E, Valckx S, Bjerke M, Engelborghs S (2017) Alzheimer's disease CSF biomarkers: Clinical indications and rational use. Acta Neurol Belg 117, 591-602.

[5] Boccardi M, Festari C, Altomare D, Gandolfo F, Orini S, Nobili F, Frisoni GB, EANM-EAN Task Force for the Prescription of FDG-PET for Dementing Neurodegenerative Disorders (2018) Assessing FDG-PET diagnostic accuracy studies to develop recommendations for clinical use in dementia. Eur J Nucl Med Mol Imaging 45, 1470-1486.

[6] Frisoni GB, Boccardi M, Barkhof F, Blennow K, Cappa S, Chiotis K, Demonet JF, Garibotto V, Giannakopoulos P, Gietl A, Hansson O, Herholz K, Jack CR, Jr., Nobili F, Nordberg A, Snyder HM, Ten Kate M, Varrone A, Albanese E, Becker S, Bossuyt P, Carrillo MC, Cerami C, Dubois B, Gallo V, Giacobini E, Gold G, Hurst S, Lonneborg A, Lovblad KO, Mattsson N, Molinuevo JL, Monsch AU, Mosimann U, Padovani A, Picco A, Porteri C, Ratib O, Saint-Aubert L, Scerri C, Scheltens P, Schott JM, Sonni I, 
Teipel S, Vineis P, Visser PJ, Yasui Y, Winblad B (2017) Strategic roadmap for an early diagnosis of Alzheimer's disease based on biomarkers. Lancet Neurol 16, 661-676.

[7] Ritchie C, Smailagic N, Noel-Storr AH, Ukoumunne O, Ladds EC, Martin S (2017) CSF tau and the CSF tau/ABeta ratio for the diagnosis of Alzheimer's disease dementia and other dementias in people with mild cognitive impairment (MCI). Cochrane Database Syst Rev 3, CD010803.

[8] Vanderschaeghe G, Dierickx K, Vandenberghe R (2018) Review of the ethical issues of a biomarker-based diagnoses in the early stage of Alzheimer's disease. J Bioeth Inq 15, 219-230.

[9] Jongsma KR, Sand M (2017) The usual suspects: Why techno-fixing dementia is flawed. Med Health Care Philos 20, 119-130.

[10] Boenink M, Cuijpers Y, van der Laan AL, van Lente H, Moors E (2011) Assessing the sociocultural impacts of emerging molecular technologies for the early diagnosis of Alzheimer's disease. Int J Alzheimers Dis 2011, 184298.

[11] Vanderschaeghe G, Schaeverbeke J, Bruffaerts R, Vandenberghe R, Dierickx K (2017) Amnestic MCI patients' experiences after disclosure of their amyloid PET result in a research context. Alzheimers Res Ther 9, 92.

[12] van Thiel GJMW, van Delden JJM (2010) Reflective equilibrium as a normative empirical model. Ethical Perspect 17, 183.

[13] Tong A, Sainsbury P, Craig J (2007) Consolidated criteria for reporting qualitative research (COREQ): A 32-item checklist for interviews and focus groups. Int J Qual Health Care 19, 349-357.

[14] Marshall MN (1996) Sampling for qualitative research. Fam Pract 13, 522-525.

[15] van Rijnsoever FJ (2017) (I Can't Get No) Saturation: A simulation and guidelines for sample sizes in qualitative research. PLoS One 12, e0181689.

[16] Hsieh HF, Shannon SE (2005) Three approaches to qualitative content analysis. Qual Health Res 15, 1277-1288.

[17] Smedinga M, Tromp K, Schermer MHN, Richard E (2018) Ethical arguments concerning the use of Alzheimer's disease biomarkers in individuals with no or mild cognitive impairment: A systematic review and framework for discussion. J Alzheimers Dis 66, 1309-1322.

[18] NVivo qualitative data analysis Software; QSR International Pty Ltd. [program], 11 version, released in 2015

[19] Johnson KA, Minoshima S, Bohnen NI, Donohoe KJ, Foster NL, Herscovitch P, Karlawish JH, Rowe CC, Carrillo MC, Hartley DM, Hedrick S, Pappas V, Thies WH, Alzheimer's Association; Society of Nuclear Medicine and Molecular Imaging; Amyloid Imaging Taskforce (2013) Appropriate use criteria for amyloid PET: A report of the Amyloid Imaging Task Force, the Society of Nuclear Medicine and Molecular Imaging, and the Alzheimer's Association. Alzheimers Dement 9, e-1-16.

[20] Barthel H, Sabri O (2017) Clinical use and utility of amyloid imaging. J Nucl Med 58, 1711-1717.

[21] McKhann GM, Knopman DS, Chertkow H, Hyman BT, Jack CR, Jr., Kawas CH, Klunk WE, Koroshetz WJ, Manly JJ, Mayeux R, Mohs RC, Morris JC, Rossor MN, Scheltens P, Carrillo MC, Thies B, Weintraub S, Phelps $\mathrm{CH}$ (2011) The diagnosis of dementia due to Alzheimer's disease: Recommendations from the National Institute on Aging-Alzheimer's Association workgroups on diagnostic guidelines for Alzheimer's disease. Alzheimers Dement 7 , 263-269.

[22] Bunnik EM, Richard E, Milne R, Schermer MHN (2018) On the personal utility of Alzheimer's disease-related biomarker testing in the research context. J Med Ethics 44, 830-834.

[23] Alzheimer Europe (2017) Discussion paper on ethical issues linked to the changing definitions/use of terms related to $A D$. Alzheimer Europe, Luxembourg.

[24] Zwan MD, Bouwman FH, Konijnenberg E, van der Flier WM, Lammertsma AA, Verhey FR, Aalten P, van Berckel BN, Scheltens P (2017) Diagnostic impact of [(18)F]flutemetamol PET in early-onset dementia. Alzheimers Res Ther $\mathbf{9}, 2$. 